\title{
DOCUMENTOS
}

\section{La Conferencia de Rubén Darío sobre Joaquim Nabuco:}

\section{INTRODUCCION Y TEXTO}

$\mathrm{U}$ $\mathrm{N}$ documento muy importante para entender a Rubén Darío en su relación con el Brasil es la "Conferencia sobre Joaquim Nabuco," 1 que fue presentada en el Club de los Diarios, Río de Janeiro, la noche del diecisiete de junio de 1912, no por el poeta mismo, quien tuvo que guardar cama por motivos de enfermedad, sino por su secretario. Las circunstancias lastimeras de esta ocasión y de gran parte del viaje de 1912 han sido comentadas por varios biógrafos y otros y no me propongo entrar más en estos detalles. ${ }^{2}$ Por extraño que parezca, nadie ha tenido en cuenta la conferencia misma sino, recientemente, el historiador Luis Viana Filho al escribir su admirable Vida de Joaquim Nabuco, aunque se mencionó su existencia en una bibliografía del profesor Daniel Wogan. ${ }^{3}$ Acrecen-

1 Una versión abreviada de esta introducción al texto de la conferencia fue leída ante el Grupo Portugués I, Modern Language Association of America, Chicago, Illinois, el 27 de diciembre de 1959.

2 Véase mi estudio "Rubén Dario and Brazil", leido en el IV colóquio Internacional de Estudos Luso-Brasileiros, Salvador, Bahía, en agosto de 1959 y destinado a publicarse integralmente en los Anais do IV Colóquio Internacional de Estudos Luso-Brasileiros, probablemente bajo auspicios de la Universidad de Bahía. Véanse también Edelberto Torres, La dramática vida de Rubén Dario (Guatemala, 1952), págs. 396-399; Daniel Wogan, A literatura hispano-americana no Brasil: 1877-1944 (Baton Rouge, La.), pág. 21; René Thiollier, "Episódios tragicómicos dé vida amargurada do poeta Rubén Dario," Revista do Brasil, Ano IX, vol. XXVI, no. 104 (agosto, 1924), págs. 302-312. Thiollier incluye un poema no coleccionado de Dario que he estudiado en "Rubén Dario and Brazil," supra.

3 A literatura bispanoamericana, pág. 22. 
temos que la conferencia no va incluida en ninguna colección de los escritos inéditos del nicaragüense. Ultimamente el doctor Antonio Oliver, director del Seminario Archivo Rubén Dario en Madrid, ha informado que el manuscrito de la conferencia no se encuentra entre los papeles archivados del poeta, y añade que "tal vez ese texto desapareciera en manos de Alberto Ghiraldo en 1925 o tal vez lo dejara en América el propio Rubén." 4 Por eso, con fines de dar a conocer este documento ahora, me he valido de una micropelícula sacada del periódico carioca $O$ Paiz del dieciocho de junio de 1912, donde aparece integralmente dicha conferencia en la página cuatro. Más abajo se discutirán algunos problemas relacionados con una edición del texto, al parecer el único existente.

Aparte su interés relativo para los biógrafos de Joaquim Nabuco, de quien hace Darío una personalísima interpretación, el texto es valioso para el conocimiento del poeta mismo y debe de considerarse uno de sus escritos más importantes sobre el Brasil. No solamente vale como obra seria nunca antes coleccionada sino que también puede proporcionarnos algunos detalles nuevos acerca de la vida del poeta durante un período decisivo en su vida, el de su participación como Secretario de la delegación nicaragüense a la Tercera Conferencia Panamericana en Río de Janeiro, desde el 23 de julio al 27 de agosto de 1906. Es útil también por arrojar luz sobre algunos aspectos del pensamiento de Darío en sus años postreros, notablemente su actitud hacia la religión que se refleja indirectamente en lo que expresó del excelso defensor de la abolición brasileña y amigo indefectible de los Estados Unidos.

Como preliminar a una discusión del texto de la conferencia habrá que advertir que Rubén Darío estimaba mucho al Brasil y su cultura. En la época de Los Raros ya había perfeccionado su conocimiento del portugués para poder leer al gran simbolista lusitano Eugenio de Castro, descubriendo luego la literatura brasileña. ${ }^{5}$ Su admiración por la civilización brasileña fue siempre considerable:

Es un país de tradiciones aristocráticas, y la cultura social se impone desde luego. Se ha aprovechado de todo lo que ha

4 Carta particular al autor del doctor Antonio Oliver, Seminario Archivo Rubén Datío, Madrid, 3 de diciembre de 1959.

5 Para algunas relaciones entre Darío y Portugal, véase John M. Fein, "Eugénio de Castro and the Introduction of Modernismo to Spain," PMLA, LXXIII (diciembre, 1958), 556-561; y mi propio estudio "Rubén Dario y Portugal," Hispanófila, Año II, no. 1 (septiembre, 1958), 23-33. 
producido la civilización europea, y se ha plasmado una característica nacional inconfundible, que podría servir de modelo en otras naciones del continente. ${ }^{6}$

Está claro que ningún brasileño ha ejercido en la obra de Darío una influencia análoga a la de Eugenio de Castro, pero sin duda la visita al Brasil en 1906 figura entre las influencias colectivas importantes en la vida del poeta, sobretodo en cuanto al desarrollo de su pensamiento en una época final de su vida. Aunque tenía muchos amigos entre los brasileños, el de más peso moral debía de ser, a juzgar por la evidencia de la conferencia que examinamos, precisamente Joaquim Nabuco.

Todavía fragmentarios son nuestros conocimientos del primer viaje que hizo Darío al Brasil en 1906 y de sus actividades durante la conferencia y se han limitado necesariamente sus biógrafos a unos cuantos datos, ya oficiales, ya anecdóticos. ${ }^{7}$ Ultimamente Antonio Oliver ha prodigado un verdadero tesoro de documentos nuevos acerca del poeta, entre los cuales hay algunos que permiten saber algo más de sus movimientos en Río: principalmente invitaciones a funciones diplomáticas, por ejemplo, dos recepciones el 27 y 28 de julio en honor del Secretario Root de los Estados Unidos. ${ }^{8}$ Todavía faltan muchos pormenores, por ejemplo los referentes a la participación por aquella fecha a bordo del buque de guerra Charleston, donde leyó Darío su "Salutación al águila." No es de extrañar que el poeta mismo, en su ligera y algo frívola "Epístola a la Sra. de Leopoldo Lugones," nos informa sólo por líneas breves y generales de su estancia en Río y entre otras cosas dice: "Yo panamericanicé - con un vago temor y con muy poca fe- en la tierra de los diamantes y la dicha- tropical." Y continúa refiriéndose a la enfermedad que puso fin a su asistencia como delegado: "A pesar de Nabuco, embajador, y de - los delegados panamericanos que- hicieron lo posible por hacer cosas buenas, - saboreé lo ácido del saco de mis penas; -quiero decir que me enfermé...."9

6 Rubén Dar'so, obras completas (Madrid, 1950-55) II, 967.

7 Consúltense las siguientes biografías: Francisco Contreras, Rubén Dario, su vida y obra (Paris, 1930), págs. 95-96; Arturo Torres-Rioseco, Rubén Dario (Cambridge, Mass., 1931), págs. 62-64; Solórzano Ocón [pseud. Ildo Sol], Rubén Dario y las mujeres (Managua, 1957), pág. 124; Edelberto Torres, Dramática vida, págs. 294-297.

8 Este otro Rubén Dario (Barcelona, 1960), págs. 46-47.

9 Obras completas, V, 1021-30. 
Respecto de esta época Darío tampoco ha dicho gran cosa en su autobiografía, aunque se refiere a un artículo en la prensa: "Ya he narrado en un diario las circunstancias, anécdotas y peripecias de este viaje y mis impresiones brasileñas y de la conferencia, a raíz de este acontecimiento."10 Al estudiar todas las referencias al Brasil en la obra publicada de Darío no he podido nunca encontrar tal artículo, que, si existe y si se encuentra, será una fuente preciosa de informes sobre el período de la conferencia panamericana.

En la conferencia valen como documentación nueva varios pormenores mencionando las circunstancias en que llegó a conocer al Embajador del Brasil en los Estados Unidos, quien más tarde tendría el título de Presidente Efectivo de la Tercera Conferencia Panamericana. A causa de su viaje juntos de Nueva York a Río de Janeiro, Darío podía trabar una amistad, formal y probablemente distante, sin lugar a dudas, que iba a dejar su huella en él. Fue gracias a él que pudo conocer a muchos de sus futuros amigos brasileños, la mayor parte de los cuales se asociaban a la conferencia. Entre las figuras de mayor resonancia literaria había, con Nabuco, Joaquim Maria Machado de Assis, José Pereira da Graça Aranha, Olavo Bilac y Antônio Fontoura Xavier, sin mencionar los conocidos de carácter más bien diplomático que literario, incluso algunos de los hombres más ilustres de la vida política del país. A Machado de Assis le dedicó un poema elogiando al gran novelista y patriarca de las letras brasileñas, en el que anunciaba un tema panamericano. Hemos podido comprobar que Darío conoció al autor de Dom Casmurro personal. mente en compañía de Joaquim Nabuco en la ocasión de un almuerzo de confraternidad en el Hotel dos Estrangeiros en el verano de 1906.11 Graça Aranha, hombre de letras y también diplomático, era de los amigos más íntimos de Joaquim Nabuco y al mismo tiempo uno de los brasileños con quien Darío más se solidarizaba. En la correspondencia de Nabuco, ${ }^{12}$ leemos que Nabuco encargó mucha parte de la hospitalidad y agasajo a los artistas hispanoamericanos con cargo diplomático preci-

10 La vida de Rubén Darío escrita por él mismo (Barcelona [1915]) pág. 257. El profesor Erwin K. Mapes, paciente investigador de los escritos inéditos de Dario en la prensa bonaerense, me informó que no dio nunca con el aludido artículo.

11 He estudiado este poema en el aludido artículo "Rubén Darío and Brazil," con las circunstancias del encuentro de Machado de Assis con Rubén Dario, con referencia a dos fotografías de éste.

12 Joaquim Nabuco, Cartas a amigos (São Paulo, s.f.), II, 228-229, (a Fontoura Xavier, 1 de diciembre de 1905); 253-254, (a Graça Aranha, 3 de junio de 1906). 
samente a Graça Aranha y a otro hombre de letras con quien se amistaba mucho Rubén, Antônio Fontoura Xavier. A éste Rubén le atribuye la inspiración de su famoso poema "Salutación al águila," según leemos en el artículo de Darío tratando de Fontoura Xavier en Semblanzas. ${ }^{13}$

"Salutación al águila" representa, si no un cambio abrupto, una etapa nueva en el pensamiento político del autor de Cantos de vida y esperanza (1905), donde, en el poema "A Roosevelt," expresó con violencia su antipatía contra la civilización anglosajona representada por el presidente norteamericano. De ahí que "Salutación al águila," con su generosa bienvenida a los Estados Unidos: "Bien vengas, mágica águila de alas enormes y fuertes- a extender sobre el Sur tu gran sombra continental...." haya sido siempre un punto de controversia acerca de la altura de Darío como poeta civil. Casi no hay crítico que no haya comentado esta volte-face del poeta en vista de sus consabidos vilipendios contra una civilización que le representaba un Caliban. Francisco Contreras, hace años, y Edelberto Torres más recientemente, no alcanzan a explicar este, para ellos, escándalo notorio del águila. Todos recordamos las palabras duras, bien que amistosas, de Rufino Blanco Fombona sobre "el divino e infame poema de usted al Aguila ... ¡Cómo no lo han lapidado a usted, querido Rubén! Le juro que lo merece." 14 Y la respuesta de Darío:

Mi querido Rufino: ¿Saludar nosotros al Aguila; sobre todo cuando hacemos cosas diplomáticas ... ? No tiene nada de particular. Lo cortés no quita lo Condor ... Los versos fueron escritos después de conocer a Mr. Root y otros yanquis grandes y gentiles, y publicados juntos con los de un poeta del Brasil ...15

Pedro Salinas ha visto este "escándalo" con diferente perspectiva:

De lo que se culpa a Darío es en realidad, de ser como era: hombre de paz, alma de concordia: Vivió el gran problema continental sincera y entrañablemente. Creyó, dudó y volvió a creer. ${ }^{16}$

13 Obras completas, II, 858.

14 Alberto Ghiraldo, El arcbivo de Rubén Dario (Santiago, Chile, 1940), pág. 198.

15 Ibid., pág. 200.

16 La poesía de Rubén Dario (Buenos Aires, 1948), pág. 239. 
Salinas lo deja bien claro que Dario esperaba que los Estados Unidos no contribuyeran forzosamente su cultura sino sus conocimientos técnicos.

Para Juan Larrea también es la "Salutación al águila" un poema clave que él estudia detenidamente como expresión del pensamiento panamericano de Rubén.

Rubén no concibe sus esperanzas en una panamericanidad puesta al servicio del imperialismo yanqui, mas sí en la libre América, en el Nuevo Mundo de Paz y Concordia que abarca, para ponerlas al servicio del Hombre, de Norte a Sur todas las latitudes ...17

Antonio Oliver declara que la "Salutación al águila" es "un poema de diplomático" escrito "en un ambiente de cortesía y de panamericanismo":

Pero afirmemos nosotros que ese poema, además de hijo de la diplomacia y del ambiente, es un poema de paz. Darío quiere creer en la paz del continente; admira el practicismo y el trabajo de los hombres del Norte y conoce, de otra parte, el exceso de palabrería que, desde la Independencia, ha disipado tantas potencias creadoras en Hispanoamérica."18

No cabe duda de que el tema del panamericanismo nunca se ha expresado con más distinción artística ni en circunstancias más propicias al entendimiento cordial de ambas las Américas. Es la Conferencia que le despierta el latente panamericanismo, a pesar de que él hubiera sido antes portavoz del antiamericanismo, en la famosa oda "A Roosevelt." Había de cambiar otra vez de actitud hacia los Estados Unidos, pero volvería luego al camino final de la paz y concordia frente a los "yanquis." Como ha dicho Oliver: "La impresión que nos da con su último viaje es la de que el poeta se desdice, se desmiente a sí mismo y que arría la bandera defendida con tanto tesón anteriormente, como parece que tambien ocurrió en 1906, al escribir en Río de Janeiro la "Salutación al águila." 19

17 "Vaticinio de Rubén Darío", Cuadernos americanos, Año I, vol. IV, no. 4 (1942), pág. 221.

18 Este otro Rubén Dario, pág. 59.

19 Ibid., pág. 52. Sobre el desartollo de las ideas politicas de Dario frente a los Estados Unidos, consúltese el bien documentado capitulo de esta obra, "El águila norteamericana y Rubén Darío". 
En cuanto a este poema se reconoce la deuda de Darío al brasileño Fontoura Xavier, pero al mismo tiempo afirmamos que indirectamente el poeta le debe cierta influencia a Joaquim Nabuco mismo, quien más que ningún otro es responsable por el éxito de la Tercera Conferencia, por las actitudes de mutuo entendimiento que se engendraban entre los delegados latinoamericanos y los estadounidenses, y por el hecho de que el Secretario Elihu Root, organizador de la conferencia y amigo de Nabuco, decidiera llegar al Brasil, realizando la primera visita oficial de un secretario norteamericano a una nación extranjera. ${ }^{20}$

No está de más recordar que la "Salutación al águila" se publicó en 1907 en El canto errante, cuyo prefacio, "Dilucidaciones," comienza con una curiosa referencia al Presidente Roosevelt, al mismo que en años anteriores había sido blanco de su invectiva. Ahora dice:

El mayor elogio hecho recientemente a la Poesía y a los poetas ha sido expresado en lengua "anglosajona" por un hombre insospechable con las nueve Musas. Un yanqui. Se trata de Teodoro Roosevelt. Ese Presidente de República juzga a los armoniosos portaliras con mucha mejor voluntad que el filósofo Platón. No solamente les corona de rosas; mas sostiene su utilidad para el Estado y pide para ellos la pública estimación y el reconocimiento nacional. Por eso comprenderéis que el terrible cazador es un varón sensato. ${ }^{21}$

Es curioso que el tono de Darío, quien seguramente no abandona su actitud de reserva frente al "terrible cazador," es, sin embargo, de apreciación, al menos de este aspecto del carácter de Roosevelt. ¿Puede ser que este pasaje, en vista de sus anteriores ataques, confirme la mudanza en la actitud de Rubén tanto hacia los Estados Unidos como hacia la figura de quien dijo "eres los Estados Unidos"? Podemos conjeturar otro ejemplo de la influencia de Nabuco, todavía no confirmada, así como la influencia subida durante la Tercera Conferencia Panamericana. Las cartas de Nabuco revelan que él era amigo personal de Roosevelt, quien a veces recomendaba a los diplomáticos recién llegados a Wash-

20 Carolina Nabuco, $A$ vida de Joaquim Nabuco, 4a. ed. (Río de Janeiro, 1958 ), págs. 415-429.

21 Obras completas, V, 945. 
ington que conocieran al más destacado de los representantes latinoamericanos en la capital.22

No olvidemos que Joaquim Nabuco era en aquel entonces no solamente el embajador más prestigioso de las Américas sino también el líder del pensamiento monroísta en Washington y también, desde la tribuna del Presidente Efectivo de la Conferencia Panamericana, el máximo proponente de la idea de la amistad intercontinental. ${ }^{23}$ Ya que su influencia personal sobre los otros latinoamericanos era grande, hay que ver a Nabuco como un hombre capaz de unificar a los latinoamericanos en la solidaridad hemisférica y de reforzar esta idea en Dario.

Si nuestra investigación del significado de Joaquim Nabuco en la experiencia de Darío ha sido, forzosamente, en gran parte circunstancial, podemos apelar ahora a un documento personal del poeta en el que, al menos en términos generales, habla de su propia estimación del gran brasileño. Después de narrar interesantemente cómo pudo conocer al Embajador, pasa a lo que es para él tema central de su conferencia, la filosofía de Nabuco expresada en su libro Pensées détachées et souvenirs, una colección de meditaciones en francés escritas por el año 1893 y publicadas en París en el año 1906. Considerados por Nabuco como su obra mejor, ${ }^{24}$ los Pensées consisten en 768 meditaciones de varia índole organizadas en tres libros: el Libro I trata preponderantemente de la ética y de la religión; el Libro II trata de una serie más variada de tópicos, incluyendo mucho sobre el arte y la literatura; el Libro III presenta todavía más variación en cuanto a sus tópicos, entre los que destacamos la política, el arte, la moral, la naturaleza, la educación, la guerra y la paz, souvenirs o recuerdos autobiográficos de la ciudad de Petrópolis, y otra vez, el tema de la filosofía religiosa. Son el cristianismo y el catolicismo los temas de más relieve dentro de los Pensées y vista esta concentración nos parece menos extraña que Darío haya pasado por alto en su conferencia los párrafos de Nabuco sobre el arte, la literatura y la estética.

22 J. P. da Graça Aranha, Macbado de Assis e Joaquim Nabuco: comentários $e$ notas à correspondência entre estes dois escritores, 2da. ed. (Río de Janeiro, 1942), pág. 82.

23 Es interesante notar que Antonio Oliver coloca la "Salutación al águila" dentro de la corriente "monroísta": "Si penetramos en el sentido político de la poesía de Rubén podríamos decir que la "Salutación al águila" está, por ejemplo, en la línea Monroe; en cambio, su "Canto a la Argentina", sus poemas "A Mirre", la "Oda a Roosevelt" y la "Salutación del Optimista" se hallan en la línea Drago, defensora del derecho de los pueblos pequeños". Este otro Rubén Darío, pág. 64 .

24 Luiz Viana Filho, $A$ vida de Joaguim Nabuco (São Paulo, 1952), pág. 321. 
También incluidos en este libro van dos importantes ensayos de Nabuco, "L'influence de Renan," y "Massangana." En aquél habla de la influencia sutil del escritor francés, influencia tanto artística como filosófica. Darío mismo había subido la influencia de Renan ${ }^{25}$ y quedaba impresionado por la narración de los conflictos espirituales del joven Nabuco ocasionados por su lectura del filósofo francés, la pérdida de su fe y su retorno luego al catolicismo tradicional de su niñez en el ingenio "Massangana" del nordeste. Los lectores de los "Nocturnos," de "Lo Fatal" y de "Divina Psiquis," entre otros poemas, se acordarán de que Darío también había caminado por la "via crucis" de la duda. ${ }^{26}$ No queremos, ni mucho menos, afirmar que los conflictos religiosos en la mente de Darío sean comparables excepto muy generalmente a los de Nabuco, quien demuestra haber recuperado un catolicismo ortodoxo, bien que vasto $y$ profundo dentro de su temperamento poético, pero hay afinidad espiritual entre los dos como se observa en la conferencia de Darío. Darío recoge una serie de los "pensées," correspondientes mayormente al Libro I de la obra, y si no los comenta muy extensamente, es evidente que los aprecia y acepta. Es evidente también que Darío ha leído varios de los mismos filósofos mencionados por Nabuco, especialmente a San Agustín, a Marco Aurelio, a Pascal, a Nietzsche y a Bergson. El mejor comentario sobre esto lo encontramos en su Historia de mis libros aunque el brasileño no se nombra:

Todas las filosofías me han parecido impotentes; y algunas, abominables y obra de locos y malhechores. En cambio, desde Matco Aurelio hasta Bergson, he saludado con gratitud a los que dan alas, tranquilidad, vuelos apacibles, y enseñan a comprender de la mejor manera posible el enigma de nuestra estancia sobre la tierra. ${ }^{27}$

$\mathrm{Y}$ ahora, en el momento culminante de la conferencia, Darío agradece a Nabuco la sabiduría de los Pensées y sobretodo el ejemplo suyo de un filósofo cristiano capaz de defender y conservar su fe incólume contra los ataques del racionalismo del siglo diecinueve:

25 Véase A. Marasso, Rubén Dario y su creación poética, ed. definitiva (Buenos Aires, 1954), págs. 5, 122-123, 198-199, 214-215, 309, 311.

26 Sobre el pensamiento religioso de Darío, véanse Arturo Torres-Rioseco, Rubén Dario: Antología poética (Berkeley y Los Angeles, 1949), págs. xxxiiixxxvii; Francis Very, "Rubén Darío y la Biblia" RI, XVIII (Dic., 1952), págs. 141-155.

27 Obras completas, I, pág. 223. 
Lo admirable es cómo Nabuco, nutrido de ciencia y de letras humanas, luchador, mundano, habiendo frecuentado los centros y las personalidades más notables de Europa, agitado en grandes problemas políticos de su país, tanto durante el imperio como en su evolución republicana; de una cultura acendrada como pocas; de un saber políglota y cosmopolita, al tanto de todos los cambios y direcciones del pensamiento universal, haya logrado mantener sus convicciones religiosas con indomable solidez, y antes bien poniendo al servicio de ellas los mismos soplos o relámpagos, de vientos y nubes negativos ... ${ }^{28}$ (págs. 329-330).

Quede esta frase arquitectónicamente organizada, que acaso nos recuerde a Renan mismo, como una muestra de uno de los característicos estéticos de la conferencia (que bien pudiéramos llamat conferencia-ensayo para resaltar sus quilates artísticos). Los límites de esta introducción no nos permiten un análisis detenido del estilo literario. Digamos simplemente que Darío apreciaba el famoso estilo oratorio o "estilo de bronce" de Nabuco, pero también, sobretodo en los Pensées, "el estilo de seda" del pensador poético, cuyas imágenes, cuya delicadeza, cuyas "sonrisas" en prosa francesa le encantaban al poeta nicaragüense que también había ensayado la creación literaria en aquella lengua, aunque sin alcanzar el asombroso manejo de Nabuco. Digamos que en su propia prosa Darío revela un estilo forénsico, grave, sonoro, periódico que no desmereciera a un comentador de Nabuco. También Darío, porque era poeta, se expresa en un lenguaje lleno de sugerencias, de matices, de figuras, dejando translucir su cariño y su estimación a Nabuco.

Las palabras concluyentes del poeta reflejan algo más que un afecto superficial; al hablar de su vida desde su primer encuentro con el autor de los Pensées, dice:

$Y$ desde entonces, desde esas escenas que evoco ante vosotros con una especie de emoción cariñosa, quedó para mí entre las figuras de mi culto mental y cordial, la de aquél cuya grande alma me subyugó más tarde en sus obras, el ahijado de doña Anna Rosa Falcão de Carvalho, el libertador, el hombre ilustre

28 Las referencias entre paréntesis se refieren al texto de la conferencia sobre Nabuco publicado en este número de Revista lberoamericana. 
que quiso el engrandecimiento de nuestro continente, $y$, en especial para su patria, riqueza, libertad, orden y progreso. (págs. 335-336).

La conferencia-ensayo esclarece cómo Dario reconocía al eminente Nabuco como líder, no solamente del Brasil sino también de toda la diplomacia latinoamericana en aquel momento. Ensalza su optimismo "cuando se refería a nuestra raza, a los pueblos herederos de la civilización latina, cuya decadencia, proclamada por la desilusión o la prisa de algunos, parecíale un tiempo de espera, tras el cual había de venir la nueva ola de vigor conductor y creador" (pág. 334). Para él, Nabuco conocía bien a los anglosajones, quienes le respetaban al distinguido diplomático que había vivido muchos años entre ellos y que sabía, según Darío, justipreciarlos sin exageraciones en pro o en contra. $\mathrm{Y}$ añade:

Por otra parte, los americanos del Norte supieron apreciar el personaje diserto, prudente, lleno de luces, que supo representar entre ellos el prestigio de una nación junto con la tradición de una raza. Y ... he de tecordar cuán útil, cuán provechosa fue, no sólo para su país, sino para la personalidad moral de todas las repúblicas de nuestro continente, la presencia de aquel ciudadano insigne en su alto puesto, en la capital de los Estados Unidos. (pág. 334).

Darío, diplomático él mismo, ha expresado una verdad confirmada por los historiadores de la época respecto de la eminencia de Nabuco en su representación de los países latinoamericanos en Washington. Finalmente, Darío estima al pacificador, al profeta del fin de las guerras, que sostiene la simple verdad con que concluye su libro de los Pensées: "Bienaventurados los mansos porque ellos poseerán la tierra."

Entre los varios escritos brasileños de Darío, es este el mejor documento que poseemos para verificar las relaciones entre él y Joaquim Nabuco. ¿Qué ha escrito Nabuco sobre el nicaragïense? Que nosotros sepamos, en su obra escrita, aquél no mencionó nunca al poeta. Hay sólo este telegrama de Nabuco recién dado a luz del Seminario-Archivo Rubén Dario, el cual recibió Dario en Buenos Aires, el 31 de agosto de 1906 a raíz de su salida urgente de la Conferencia: "Obrigado afectuosa 
lembranza [sic] felizes votos prompto restablecimiento [sic]." 29 No sabemos cuál era esta "lembranza"; si era acaso un libro de Darío, el inventario de la biblioteca de Nabuco no dice nada a este respecto ni tampoco de otros libros hispanoamericanos. ${ }^{30}$ No hay evidencia para indicar que Nabuco hubiera leído a Dario. Efectivamente, según afirman sus biógrafos, no le interesaba a Nabuco la poesía contemporánea.

Antes de la muerte de Joaquim Nabuco en 1910, podemos concluir que los dos hombres se visitaron sólo una vez. Según declara Darío mismo, en entrevista con la prensa de Río de Janeiro en 1912, habia visitado a Nabuco una vez en Nueva York. ${ }^{31}$ Esto era en 1908. Seguro que eran amigos Darío y Nabuco pero de la naturaleza de sus relaciones amistosas sólo podemos inferir leyendo el texto de la conferencia que se presenta aquí. Si dejamos aparte las diferencias manifiestas de temperamento y personalidad de estas dos figuras, se puede afirmar que los valores del brasileño son filosóficos mientras, en cambio, los del nicaragüense son estéticos. Hay, sin embargo, sectores de preocupación ética y social donde coinciden sus actitudes y pensamientos, $y$ en estos venimos haciendo hincapié. Darío y Nabuco eran además espíritus afines en sus predilecciones humanísticas, en su $W$ eltanschauung cosmopolita, en su veneración por la cultura europea y en especial la francesa. Directa e indirectamente Darío le debe bastante por ciertas experiencias decisivas en el Brasil. Tal vez le estuviera también Nabuco agradecido a Darío, como lo están actualmente muchos brasileños, por el ejemplo de un poeta que ganó un renombre intercontinental logrando, como lo habia hecho también Nabuco de manera diferente, la creación de nuevos valores dentro de la cultura iberoamericana.

\section{EL Texto}

Se ha notado que el texto de la conferencia sobre Joaquim Nabuco que publicamos ahora se basa en una micropelícula sacada del influyente periódico de Río de Janeiro O Paiz, del 18 de junio de 1912, en la pá-

29 Oliver, Este otro Rubén Darío, págs. 46-47.

30 Osvaldo Melo Braga, Bibliografía de Joaquim Nabuco (Río de Janeiro, 1952), págs. 177-265.

31 Anónimo, "Pequenas entrevistas", en $A$ Imprensa, Río de Janeiro, 11 de junio de 1912. A. Oliver lo confirma, poniendo la fecha de 1908. Este otro Rubén Darío, pág. 52. 
gina cuatro ${ }^{32}$. Como observamos en la introducción, este texto debe considerarse el único existente. Aparece bajo la cabecera en portugués, "Rubén Darío," seguida abajo por otra, "A conferência sôbre Joaquim Nabuco," las dos en mayúsculas y sin signos diacríticos ni de puntuación. Siguen tres párrafos cortos en portugués (que transcribimos en su forma moderna) que presentan y explican las circunstancias de la conferencia. El resto del artículo lo constituye la conferencia misma que consiste en aproximadamente 5.200 palabras en español.

Para nuestra edición del texto, el mayor problema ha sido la existencia de unos doscientos errores tipográficos. Por la índole de los errores, principalmente palabras trabucadas, se infiere que el tipógrafo del periódico carioca, sin duda de habla portuguesa por las muchas instancias en que da forma portuguesa a varias palabras, trabajaba a base de un manuscrito para él a veces poco legible. No es posible saber si era del puño mismo del nicaragüense. Tambièn hay evidencia de algunos descuidos de parte del tipógrafo, a juzgar por las repeticiones innecesarias de palabras o de líneas en el texto español, aunque en el texto más corto en portugués, no hay errores.

Mi tarea ha sido la de restablecer hasta lo posible el texto del manuscrito que debía de servir al tipógrafo. También he deseado modernizar la separación de palabras, la consolidación de palabras escritas en el texto original con guión y la ortografía de unas cuantas voces, según las normas del Diccionario de la Real Academia. Con poquísimas excepciones he dejado sin tocar las mayúsculas que aparecen en el texto y la puntuación; ésta última, al parecer, no le of recía problema al tipógrafo. El sistema de puntuación es en general consecuente y acaso represente los toques mismos del autor, que tal vez puntuara de acuerdo con un deseo de realzar el tono oratorio de su conferencia. Hago excepción por la introducción de los puntos iniciales de interrogación y de admiración, faltos evidentemente en las fundiciones de $O$ Paiz; también, por la introducción de la comilla simple donde había comillas en el texto para indicar una cita dentro de otra. Además, las comillas en ciertos casos han sido trasladadas para indicar más exactamente el límite de alguna cita de los Pensées. He suprimido palabras o líneas repetidas inútilmente en el texto.

32 Quiero agradecer públicamente a mi amigo Jayme Villa Lobos la obtención de esta micropelícula en la Biblioteca Nacional, Río de Janeiro. 
Afortunadamente ha sido posible rectificar la mayor parte de las palabras trabucadas con simplemente referirme al sentido del pasaje. Ya que tales errores son obvios y fáciles de subsanar dejo tales enmendaciones sin comentario. Pero, cuando no fue posible resolver una duda así y cuando había que recorrer a una enmendación incierta y sobre todo cuando ésta era importante para entender el significado total de un pasaje, he incluido una nota al texto.

Las anotaciones de los "pensées" citados completa o parcialmente en la discusión de las ideas de Nabuco, se justifican no solamente por su interés intrínseco sino también porque a veces ayudan mucho a aclarar el sentido de frases o palabras trabucadas por el tipógrafo. Otro tanto podemos decir de ciertas notas que iluminan alusiones o que sirven al lector que quiera ahondar en el texto o en las fuentes de Darío.

University of Texas

Fred P. Ellison

\section{RUBEN DARIO}

\section{A CONFERENCIA SOBRE JOAQUIM NABUCO}

No lindo salão do Club dos Diários, reuniram-se ontem, à noite, a nossa sociedade elegante, as altas autoridades do país e as mais brilhantes personalidades do nosso meio intelectual, para ouvir Rubén Darío, na sua conferência sôbre Joaquim Nabuco.

Infelizmente, não foi possível àquele fino auditório ter a emoção de arte que certamente Rubén Dario lhes proporcionaria, com a sua palavra quente, sonora, cheia de efeitos surpreendentes. $O$ ilustre poeta, atingido por uma súbita e violenta enfermidade, foi obrigado a guardar o leito e não pôde comparecer.

A conferência foi, porém, lida pelo secretário do emérito escritor, o Sr. R. Bueno e, do extraordinário valor dessa magnífica peça literária, bem poderão aquilatar os nossos leitores, porque passamos a transcrevêla na integra: 


\section{Señoras:}

Señores:

Es algo como una emoción afectuosa lo que siento hoy, al ocuparme ante un auditorio brasileño de la ilustre personalidad que tuvo por nombre Joaquín Nabuco. Comprendo verdaderamente, ante su memoria, la íntima e intraducible significación de una palabra de vuestra lengua, la palabra "saudade." Yo tuve la feliz oportunidad de conocer y tratar a aquel varón tan eminente como lleno de virtudes, a aquel diplomático filósofo, a aquel gentil hombre que cultivó como pocos su carácter y su talento, procuró hacer el bien a sus semejantes y adoró a su Patria. Nadie duda de que en el panteón de vuestros grandes hombres ha de ocupar uno de los lugares preferentes, pues es condición de las naciones que tienen la cultura y los nobles entusiasmos de la vuestra, el tener para sus héroes y próceres del pensamiento o de la acción un glorioso reconocimiento.

Cuando yo vi por primera vez al preclaro embajador, estaba ya en sus postreros años; había nevado ya mucho sobre su hermosa y aristocrática testa de dominador; pero tanto en su talante como en su conversación fluída, oportuna, sensata y sabia, existía el calor inconfundible de algo que se diria una juventud eterna, la que les da a ciertas almas escogidas los dos mayores dones sobre la faz de la tierra: la fe y el entusiasmo. Era en días anteriores a la reunión de la Conferencia Panamericana de Río de Janeiro.

Varias delegaciones hispanoamericanas y la de los Estados Unidos, se encontraban reunidas a bordo del barco inglés que conducía hacia la tierra del Brasil. Yo formaba parte de la delegación de mi patria nativa. $Y$ pude observar desde el primer momento que aquel caballero alto, de ojos penetrantes y buscadores, a través de los espejuelos, de gallardo porte, de modales de gente "nacida," y de un hablar que, cuando trataba de algo que le entusiasmase, guardaba en parte "a sonoridade de seu estilo bronze," frase de Arthur Orlando, ${ }^{2}$ era implícitamente considerado por todos como

1 El sentido del pasaje parece requerir "les da", aunque el texto de O Paiz tiene "se da", error tipográfico.

2 Crítico pernambucano (1858-1916). ¿Le habría oído Darío en julio de 1906 cuando se detuvo allí brevemente en Recife, Pernambuco, en compañia de Nabuco, rumbo a la capital brasileña? Sobre el estilo literario de Nabuco, véase el ensayo de Graça Aranha en su Machado de Assis e Joaquim Nabuco: comentários e notas à correspondência entre estes dois escritores, 2da. ẹd. (Rio de Janẹiro, 1942), págs. 73, 247. 
un personaje central, como un director, y ello poniendo aparte su superioridad protocolar y el estar llamado a presidir las sesiones de la Conferencia, de la que en verdad era alma y motor, desde su embajada de Washington.

Se veía, desde luego, el gran señor, un gran señor de otros tiempos, y su urbanidad estaba siempre llena de dignidad. Ibamos en el barco algunos que a la función diplomática agregábamos la consagración o el amor a las letras, y claro está que sabíamos quién era mentalmente aquel miembro de la Academia brasileña. Así, en los instantes en que no se diplomatizaba le buscábamos con preferencia y le escuchábamos con placer. De mí diré que nunca he oído conceptos más claros, hondos y bellos, expresados por una boca sabia y con tan largo caudal de experiencia.

Comprendía, como dice la palabra emersoniana, cuán pobre es la naturaleza y la fortuna comparada a nuestras riquezas interiores y personales. Aquél era un millonario de ideas; pero no las comunicaba profusas y desordenadas, sino escogidas y con la seguridad de su valor, como las finas perlas $y$ los diamantes excelentes.

Corregía él, en ratos de vagar, las pruebas que una casa parisiense le había enviado, de un libro suyo escrito en francés, Pensées détachées et souvenirs, el cual libro será el tema principal de que trataré ante vuestra benévola atención. De esa obra ha dicho él: "Los reflejos del ideal recuerdan las pequeñas especies que la noche produce en silencio en su oscuridad. Para fijar su contorno viviente es preciso poder discernir en la luz extinta en que nacen y mueren en seguida. Como ellas, toman en general los tintes grises de la tarde, a lo más, el buriel amarillo obscuro del crepúsculo; no es sino en los espíritus muy altos y muy puros que pasan a veces teniendo alas de oro. Así, tales imágenes no pueden ser tratadas sino a la sombra misma de la meditación que las ha hecho brotar. No es, pues, sin temor que me atrevo a exponer en pleno día algunas de esas impresiones inasibles que se destruyen al pensamiento como las falenas a la luz." 3 Como veis, el estilo de bronce se tornaba a veces estilo de seda. Su libro está compuesto, según su propia advertencia, de notas, casi todas escritas en Petrópolis, en 1893, cuando el autor trabajaba en una obra de la cual los fragmentos "Massangana" y "La influencia de Renan" eran capítulos. Nadie, que yo sepa, escribe "pensamientos" ex profeso. Los de Marco Aurelio son anotaciones autobiográficas

3 Las págs. del prefacio a los Pensées détachées, que cita entero Datio, no llevan números 
o reflexivas, para él mismo, conforme con el título griego de su libro. Los de Pascal, bien se sabe que eran materiales para una obra coordinada; otros, como los de F. de la Rochefoucauld, o Joubert, son destilaciones que gotean en máximas. Solamente a los señores Bouvard y Pécuchet's se les ocurriría: "voy a pensar; voy a escribir un volumen de pensamientos." $Y$ luego, las ideas cristalizadas surgen solas, en la usina cerebral.

Así Joaquín Nabuco, en sus cogitaciones, en su labor metódica de obras orgánicas, fue recogiendo esos hallazgos, esas súbitas revelaciones, que formaron después un volumen inapreciable. Tenía motivos ancestrales, como el pío Antonino, para mantener las tres condiciones morales que él señalaba en otro gran brasileño: 5 el patriotismo, el desinterés y la tolerancia. Ellas aparecen en el curso de sus ideas, y ellas fueron características en su noble existencia.

"Vir bonus," sus pensamientos tenderían siempre a lo alto, a lo justo, a lo bueno. Meditó mucho en el misterio de su propio espíritu, y fue siempre alentado por una religiosidad convencida y voluntaria que daba a su rebusco genial nuevos alientos en cada golpe de ala. Su libro, al haber sido publicado en Europa por un europeo, y en una época en que el industrialismo intelectual y la inanidad de la crítica no habían aun aparecido, habría tenido una vasta resonancia. Cuando se publicó la obra de Nabuco en París, un escritor importante cuya fecundidad que inquieta podía ser precaria excusa para su lamentable falta de noticias, se ocupó de ella en el grave Temps. He nombrado a M. Emile Faguet. ${ }^{6}$ No había llegado a sus oídos el nombre de una de las más grandes figuras ibéricas, del luminoso sustentador del abolicionismo de la esclavitud en el imperio del Brasil, del célebre parlamentario, del famoso diplomático, del autor de obras aplaudidas, del orador, del pensador, y llegó a dudar si aquel nombre, Joaquín Nabuco, era un pseudónimo... Cierto que se puede

4 Bouvard y Pécuchet (París, 1881), novela de Gustave Flaubert (1821. 1880); los dos protagonistas aludidos en el título simbolizan la fatuidad de la clase media.

5 No he podido verificar este elogio, que en términos generales pudiera aplicarse al padre de Nabuco, retratado por el hijo en Um estadista do Império: Nabuco de Araúio, 3 tomos (Río de Janeiro, París, 1898-1900).

6 El artículo de Emile Faguet $(1847-1916)$ apareció en la sección "Les annales politiques et littéraires", del Temps, París, 29 de septiembre de 1907. Cf. Osvaldo Melo Braga, Bibliografia de Joaquim Nabuco. (Río de Janeiro, 1952), págs. 37, 172-177, que reproduce este artículo. Otra reseña de los Pensées détacbées por Vicenzo Morelli [pseud. Rastignac] traducida de la Tribuna de Roma, sin fecha, en el Jornal do Comércio, Río de Janeiro, 14 de enero de 1907, se incluye en Graça Aranha, Machado de Assis e Joaquim Nabuco, págs. 203-207, la cual, empero, no tiene relación con la conferencia de Darío sobre Nabuco. 
recordar el conocido, y que en este caso es flagrante la ignorancia de la geografía intelectual. Pero con todo, la perspicacia del académico y la conciencia del estudioso, descubrieron a "alguien" en ese libro, que debía haber causado asombro, si no ya por el tesoro psicológico y trascendental que contiene, por estar escrito en un francés que aplaudiría un Taine, o un Renan. ${ }^{7}$ No conozco ningún otro juicio además del de M. Faguet, quien, posiblemente a causa de esa famosa consagración que se exige de París para toda obra del entendimiento humano, era de cualquier parte de donde llegue, se creyó en el caso de emplear el conocido tono protector, sin darse cuenta de que si se exprimiese buena parte del copioso amontonamiento de su propia obra no se recogería la mitad de los elíxires espirituales que se concentran en el volumen nabuquiano. Con todo, el colaborador del Temps, supo señalar más de una belleza y profundidad en el libro precioso, y váyase lo uno por lo otro.

Haré notar ante todo, que lo que distingue a Nabuco pensador, es una inmensa concepción de universal piedad. Desde el comienzo de su libro al clásico "Primus in orbe deos fecit timor,"8 él agrega que, ciertamente, es el temor, o el terror, el que hizo los primeros dioses, pero fue el terror del amor. El ve en la religión "la potencia paternal de Dios."9 Y él mira, en el ambiente sano de sus ideales, como el mayor bien el bien de la creencia, y consideraba que la duda era la más temible de las esclavitudes del espíritu. ${ }^{10}$ Cierto que así no se piensa en tales o cuales jardines epicúreos, ni Nabuco hubiera aceptado la constante sonrisa, ni hubiera escrito cartas a los "compagnons" en nombre de la R. S.11

Se diría que al pensador su tierra enorme y ardiente insufló fuerzas especiales; y su espiritualismo le condujo a la realización de obras tras-

7 Sobre su dominio del francés, véase lo que escribió el Embajador de Francia en Washington, J. Jusserand (1847-1916), cuando falleció allí Nabuco en 1910. Citado por Carolina Nabuco, A vida de Joaquim Nabuco, 4a. ed. (Río de Janeito, 1958), págs. 464-465.

8 Pensées détacbées, Lib. I, núm. 1, pág. 1. Véase Petronii Satyrae et Liber Priapeorum, redactado por F. Buecheler (4a. ed.; Berlín, 1904), fragmento XXVII, pág. 114. El primer verso del poema, atribuido a Petronio, reza "primus in orbe deos fecit timor, ardua caelo..." Cf. también Estacio, Tebaida, III, 661; también " Twas onely feare, first, in the world made gods," de Ben Jonson, Seianus, redactado por W. D. Briggs (Boston, London, 1911), II, ii, linea 24. 9 I, ii, 1. En esta forma se referirá en adelante a los "pensées" de Nabuco, por libro, número del "pensée" y página, en la edición de 1906.

10 I, iii, 2.

Il Esclarece Darío estas mayúsculas en "Un poeta socialista, Leopoldo Lugones," en Rubén Dario, obras completas (Madrid, 1950-1955), IV, 839: "La revolución social - Erre Ese, como dicen entre ellos los afiliados - es para él un deseado advenimiento ..." 
cendentes. ¿Qué mayores esparcidores de cívicas alegrías que los creadores de verdadera libertad? El nos dirá: "La religión ${ }^{12}$ no es un impedimento para ningún goce, ni ninguna libertad. Un sistema negativo cualquiera cuyo grano cae sobre el espíritu, es como la liana parásita que, de rama en rama, enlaza al árbol y lo seca." Y agrega esta "fioretta": "En cuanto a la fe, no es sino un pajarito que se posa sobre el techo de follaje y canta en las horas en que Dios escucha."13 Mas, su religiosidad no le hace sino reconocer que las alturas místicas son para naturalezas muy de excepción. En cuanto a los conflictos entre la religión y el espíritu científico, ved lo que contiene este principio apotegmático que nos lleva muy lejos de todos los Draper:14 "La ciencia es en verdad el espejo de lo infinito, pero un espejo roto en mil pedazos, que sólo la religión puede juntar."15 Sustituyamos, si gustáis, la palabra "religión": ¿no se diría una anticipación a los conceptos del más actual bergsonianismo? Ciertamente, él no niega el poder de los descubrimientos científicos, la audacia de las especulaciones, el progreso humano; mas, mira en el principio religioso un freno, o según su expresión, un "garde-fou."16 Penetra a veces en los problemas teológicos, y siempre se encuentra algo de consolador, como cuando, al hablar de lo que él llama la contabilidad di. vina, ${ }^{17}$ en que se nos pone en el deber lo que nosotros creeríamos en el haber y al contrario, piensa que "un jurado de ángeles no podria juzgarnos con ninguna justicia humana, como nosotros no juzgaríamos con la equidad animal las faltas de las bestias."18 Se pensaría en Soedenborg. En realidad, él no intentó siquiera explorar las tierras incógnitas - " hic sunt tenebrae"19- por donde, más allá del bien y del mal, perdió su brújula el poeta de Zaratustra. El escepticismo es para él antisocial; la creencia vincula a los hombres. ¿ ¿Y la razón? "Si cada cual por deber

12 Véase I, vi, 3: "La religión n'est un empêchement a aucune joie..." que ayuda a rectificar el error en el texto, que tiene "la libertad no es un impedimento ..."

13 Loc. cit.

14 Dario al parecer se refiere a John William Draper (1811-1882), médico, químico, historiador inglés (History of the Conflict Between Religion and Science, 1874) que sostenía la tesis de que el desarrollo social queda dominado por las leyes naturales.

$151, x, 3$.

16 I, xiii, 4 .

17 I, xvi, 5 .

18 Loc. cit. Cf. la misma idea en I, xviii, 6.

19 El texto lleva "tenebriz," evidente error por "tenebrae." Mis investigaciones, sobre todo en antiguos libros de cartografia, no me han permitido todavía verificar el origen de esta cita del latín.

20 I, $x i x, 6-7$. 
de sinceridad se sujetase únicamente a su propio juicio, llegaría pronto el reino de la ignorancia. Mi deber, dice, es relegar mi razón a su lugar, verificado por medidas casi científicas, es decir, al rango a que tiene derecho entre las otras razones, o, si se trata de religión, enfrente de la gran razón universal. En el fondo, lo que llamáis nuestro propio juicio, no es en general más que la elección más o menos consciente que hacéis de una autoridad sobre la vuestra." 21 Es la sumisión ${ }^{22}$ de la razón, de San Agustín, que Pascal reduce a un justo medio, señalando lo que él llama los dos excesos: excluir la razón, no admitir más que la razón. ${ }^{23}$

En los pensamientos de Nabuco la profundidad va casi siempre a través de una bella imagen, lo que indica la frecuentación de los poetas, de los libros santos. En ocasiones se encuentra con algún autor antiguo, coincide con otros pensadores; pero su concepción personal, su poder imaginativo, y su dominio verbal, constituyen su originalidad. "El misterio, escribe, no estrecha el horizonte, lo alarga."24 "Toda idea es un espejo de Dios para quien puede pulirla a lo infinito."2s Muy lejos del clericalismo, reconoce sin embargo la importancia de la iglesia; y la necesidad de una base religiosa para la permanencia de la moral. ${ }^{26}$ Llama la atención ante los inconvenientes de acercarse al abismo que diríamos pascálico: "No miréis mucho vuestra fe: toda mirada por dentro demasiado prolongada y atenta, es peligrosa, se arriesga desmontar el aparato mismo de la visión. El ojo no ha sido hecho para ver su propio fondo, ni la fe tampoco." 27 Por otra parte jamás pasó por su mente la idea de proselitismo. Afirmará postulados como éste: "El hombre irreligioso puede conocer la paz del espíritu, pues no sufre de un sentido que nunca ha tenido; el hombre religioso privado de creencias, ya no la conocerá más." 28 El deber mismo, necesita de un principio de religiosidad, "que es su salario," 29 y sin el cual se pondría en huelga.

21 I, xxxix, 14-15.

22 El texto trae "En la sumisión..." error por "Es la sumisión..." Darío pensaría en los "pensées" núms. 269 y 270 de Pascal, donde discute la idea de la sumisión de la razón. Véase Blaise Pascal, Pensées, ed. León Brunschvicg, II (París, 1904), 197-198. II, 186.

23 Cf. Pascal, "pensée" núm. 253, sobre la exclusión de la razón, ibíd.,

24 I, lii, 20.

$25 \mathrm{I}$, liii, 20.

26 I, lviii, 22; lix, 22-23; lxii, 24 .

$27 \mathrm{I}, \mathrm{lxv}, 25$.

28 I, Ixix, 27.

$29 \mathrm{I}, \mathrm{lxxv}, 29$. 
Hay dos pensamientos, al escribir los cuales ha recordado la obra nietzcheana, pero "à rebours." "El superhombre, dice, es el asceta, el santo; ésa es una idea propia de todas las religiones. Lo que es propio en pensamiento solitario, es el superhombre fin de sí mismo. Esa también es una concepción muy antigua. Se puede ahondar y descubrir mucho en la leyenda de Satán; no se le puede agregar nada." ${ }_{0} \mathrm{Y}$ luego, como si parase ante su memoria la figura del filósofo de Sils-Maria:31 "Hay locuras que provienen de que el espíritu sube tan alto, que no puede descender y se pierde en el vacío." $32 \mathrm{Y}$ una observación que se diría de un Luis Veuillot, ${ }^{33}$ o un fulminante Leon Bloy: "La literatura religiosa es tal vez la que produce el mayor número de libros mediocres, pues la uniformidad es la regla y 'l'effacement' la inspiración." 34

Cuán bellos libros de alta belleza religiosa habría escrito él, que tiene páginas de una emoción suprema y de un alcance prodigioso, y en que al par que la transparencia de su convicción se adivina el hondo conocimiento de los místicos, y la meditada lectura de doctores y de filósofos. $Y$ algo en que insiste, es en que la religión no debe ser un motivo de tristezas, antes bien una esparcidora de goces: "être la touffe de fleurs à la croissé du pauvre." "La mortificación, según él, no sería admisible sino para reprimir la tristeza." 35 Es un consolador este hombre que piensa en que hay que dulcificar, por Dios mismo, la amargura de lágrimas de la vida. Pascal, con menor salud, con mayor cantidad de humor melancólico, se junta con Hobbes, y antes que él proclama que el odio mutuo es lo natural de los humanos.

Su religiosidad no aparta el "figmentum malum."36 Todo espíritu que crea que la religiosidad no excluye la vida, ni la sana alegría, preferirá el "sursum" del americano a la dolorosa fatalidad del gran Blas.

Lo admirable es cómo Nabuco, nutrido de ciencia y de letras humanas, luchador, mundano, habiendo frecuentado los centros y las personalida-

301 , 1 xxix, 31 .

31 Friedrich W. Nietzsche (1844-1900), quien veraneaba en Sils-Maria, Suiza. Para el interés de Dario en este pensador, véase Obras completas de Rubén Dario, ed. citada, IV, 710-717.

32. I, $\operatorname{lxxx}, 31$.

33 En el texto "Venillob," error por "Veuillot," redactor de L'Univers, París, atacado por I. Bloy. Cf. Obras completas, II, 323.

34 I, Ixxxv, 32.

35 I, xciii, 35 , incluso la cita en francés.

36 Véase Pascal, Pensées, ed. citada, núm. 453, II, 366: "Ce vilain fond de l'homme, ce figmentum malum..."También loc. cit., nota 3 de Brunschvicg sobre el uso biblico de figmentum. 
des más notables de Europa, agitado en grandes problemas políticos de su país, tanto durante el imperio como en su evolución republicana; de una cultura acendrada como pocas; de un saber políglota y cosmopolita, al tanto de todos los cambios y direcciones del pensamiento universal, haya logrado mantener sus convicciones religiosas con indomable solidez, y antes bien poniendo al servicio de ellas los mismos soplos o relámpagos, de vientos y nubes negativos. $\mathrm{Y}$ es que en su ánima privilegiada había una candencia de oro puro, y que le hacía refractario tantó a la palúdica indiferencia, como al desesperante pesimismo; por su religiosidad comprendía, conforme con su expresar, el valor de la vida y el precio de la muerte. La religión para él sería razón del porvenir, en la transmisión individual por la descendencia. ${ }^{37}$ De repente, notará, con un sentido de inquietud moderno que vuela a lo inmemorial de las creencias: "El alma se estrecha. Se siente en el 'Miserere', por ejemplo, en esos potentes 'dele iniquitatem meam, amplius lava me, in peccatis concepit me mater mea', 38 la traza, la sombra de pecados colosales alzados ante la conciencia y conmoviéndola con remordimientos que eran terrores. Esos antiguos remordimientos no son ya posibles; como las armaduras de antes, el alma moderna no sabría ya llevarlas. No se encontraría hoy, ni aun entre los locos, ninguno de esos levantamientos gigantescos de la conciencia, de esos fantasmas interiores desaparecidos. No tendríamos ya la fuerza necesaria para producirlos. Nuestras almas no se desdoblan ya sino en virtudes y en pecados raquíticos." 39 Pensaríase en una evocación que surgiera al musical verso de Verlaine: "Dans un palais, soie et or, en Ecbatane .. .;" 40 en sugestiones de Maldoror; ${ }^{41}$ en formidables ensueños y bíblicas visiones pentapolitanas.

En medio de los altos puntos de vista, no deja de aparecer, de cuando en cuando, alguna sonrisa, cuya delicadeza no veza ${ }^{42}$ a resolverse en

37 Cf. I, cri, 39: "Ce sont les enfants, nos enfants, qui posent d'une façon définitive le grand problème du monde moral. Si l'humanité était stérile, la religion ne lui serait jamis venue à la pensée."

38 I, cxii, 41-42. Nabuco incorpora partes de los versos 3, 4 y 7 del salmo I de la Biblia Sacra Vulgatae, ed. Michael Hetzenaver (Innsbruck, 1906).

39 Completa el "pensée" citado, loc. cit.

40 Darío confunde la segunda preposición del verso de Paul Verlaine, "Dans un palais, soie et or, dans Ecbatane ...," "Crimen amoris," de Jadis et naguère (1885), en Oeuvres poétiques complètes (Paris, 1954), págs. 256-259.

41 Protagonista de los blasfemos y alucinados Chants de Maldoror (1869. 1874) de Isidore Ducasse [pseud. Comte de Lautréamont], en sus Oeuvres complètes (París, 1956), págs. 123-358. Para un estudio de Darío sobre él, véase Obras completas, II, $435-442$.

42 El texto tiene "veza a,", posiblemente trabucada. Tal vęz mejor solución sería "viene a:" 
ironia. "El hombre debe parecer, dice, terriblemente exagerado a los seres superiores, con su noción de infinito, de absoluto, de eterno, aplicada a todo lo que es de la otra vida." 43 O bien: "Si el hombre viera a Dios, sin estar antes preparado, se sentiría probablemente desilusionado; encontraría la realidad inferior a la idea que él se formaba de ella. En efecto, prosigue, Dios mismo, no sabría contentar la aspiración al infinito, que es la enfermedad del hombre, una megalomanía intelectual, cansado por su ignorancia del objeto deseado y por el esfuerzo de una imaginación impotente para concebirlo." 44 Aún $^{45}$ encontramos aquí la antigua influencia renaniana a que él se refiriera en un admirable capítulo.

En seguida, aparecerá una duda, o más cierto, ${ }^{46}$ una negación de la futura perfectibilidad humana. No es negar el progreso, a la manera de Lamartine, en su aspecto material. El hombre adelantará mucho aún; has$\mathrm{ta}^{47}$ admite el pensador la posibilidad de que encuentre el árbol de la vida del Genesio; pero lo más probable, es que todo tenga un fin y que la vida de las sociedades se gaste como la de los individuos. Y esta hermosa frase que hace meditar: "Si el progreso debiera ser ilimitado, Dios hubiera reservado los atenienses para el fin." 48 Prevé con un "tal vez" que no llega a la esperanza, anticipaciones, como Wells, ${ }^{49}$ que ponen la ciencia al servicio de los últimos esfuerzos del hombre sobre la tierra moribunda. Hoy somos ya viejos.

Otra sonrisa a lo Renan: "¿Es preciso, necesariamente que, en el cielo, se sepa la trigonometría o la física? ¿Se podia, asi, concebir existencias muy superiores a las nuestras y capaces de pasar nuestro bachillerato? La ley de Arquímedes, ha debido, con todo, parecer al Creador muy ingeniosa." 50 Y esta afirmación decisiva: "Los sistemas filosóficos no son en el fondo más que inmensos trabajos para sostener la idea del deber a la cual se hubiera quitado ese soporte natural, que es Dios." 51 Su deísmo

\$3 I, xciv, 42-43. La versión francesa esclarece que "su" en la traducción se refiere a "el hombre."

$44 \mathrm{I}, \mathrm{cxv}, 43$.

45 "Nun" en el texto.

46 Propongo "más cierto" por "mar fiero" en el texto.

47 Leo "mucho aún: hasta...." enmendación de tres palabras seguidas trabucadas por el tipógrafo: "mudeo aim; Janer..." Cuadra con el sentido del "pensée" I, cxix, 44-45, al que se refiere aquí Darío.

48 La cita forma parte del "pensée" en loc. cit.

49 Véase el artículo sobre Herbert G. Wells (1866-1946) en Obras completas, II, 915-920, donde Dario subraya el don profético del novelista.

50 1, cxxv, 47.

51 I, cxl, 51. 
tiene profusas raices, y arriba le forma una cúpula de azul que abriga su entendimiento. Mas él mismo, no dejará de indicar: cuidado con las alturas demasiado elevadas. Sabía bien que el divino alpinismo ocasiona los más irresistibles vértigos.

A través de toda esta colección de concreciones espirituales, de extractos de raciocinios, la religión ocupa un largo y principal lugar. Hay una página exegética sobre el "Padre nuestro," en que a través del misterio de la oración se ve el reflejo resplandeciente de lo absoluto.52

Si la plegaria llega a desaparecer, por obra de la pseudociencia futura, vendrá la más fría y nocturna de las soledades morales. ${ }^{53} \mathrm{El}$ pensador anima, consuela, hace tener esperanza, aparta del sendero de tinieblas. ¿Los adelantos en el estudio de la psicología, de laboratorio?54 "Querer conocer el espíritu por el cerebro, es como buscar en el violín el Genio del compositor que ha tocado en él." 55 Y luego: "Cada descubrimiento en psicología volverá al contrario el problema psicológico cada vez más complicado, pues todo descubrimiento trae una serie nueva de desconocidos." $"$ Un libro, en realidad podria escribirse, para comentar las percepciones, los hallazgos, los descubrimientos de estrellas en el cielo filosófico, de este varón bienhechor que hablaba en áurea lengua, y que tenía de los platónicos alejandrinos, de los videntes de la mística, de Novalis. Otra piedra preciosa: "Es la tierra la que gira alrededor del sol. Es Aristóteles quien gira alrededor de Platón." 57 ¡Qué obra de fuerza y de gracia había dejado al mundo de las ideas, el egregio brasileño, si hubiese consagrado toda su existencia únicamente a la labor intelectual! Mas no lo lamentemos tanto, ya que transmutó las energías, para la realización de acciones memorables, que forman parte de la riqueza moral y de la gloria de su patria. "Yo me consagré, ha dicho él, no a la literatura estéril, sino a la acción y a la lucha por la abolición de la esclavitud." 58

Me he detenido de manera principal en los pensamientos sobre problemas morales y religiosos, porque ellos constituyen la parte básica de

52 I, clxvii, 60-61.

53 Paráfrasis de I, clxxii, 63-64.

54 I, clxxxiv, 67-68.

55 I, clxxxvii, 69.

56 I, clxxxviii, 69.

57 I, cxcviii, 72.

58 Esta cita no se refiere a los Pensées détachées sino a la vida misma de Nabuco, campeador triunfante de la causa abolicionista. No podemos verificarla en la obra de Nabuco. Alceu Marinho Rego, Nabuco (Río de Janeiro, 1951), pág. 71, le atribuye un dictamen semejante al que recuerda Darío: "Os livros devem ser todos êles campanhas." 
su libro, y porque ellos explican el método de auto-cultivo de aquel fuerte cerebro. Todos sus demás puntos de vista, derivan del momento en que pudo dirigir su barca, diríamos con más actualidad su aeroplano, hacia un rumbo fijo, esto es, hacia las regiones de su ideal espiritualista. Su motor potente y seguro es todo de amor, un amor cósmico, de propulsión divina. Así todo lo ve desde su altura, y con una maravillosa lucidez interpreta más de un misterio vital. El nos dará nuevos modos de explicar difíciles incógnitas, sobre la familia, sobre el matrimonio, sobre la pasión amorosa, sobre la mujer.

Nuestro moralista deja su apotegma siempre aromado de una esencia simpática. Y su moral no pone ningún peso sobre las alas del alma ${ }^{59}$ humana. El definirá la felicidad como la "admiración de lo que es bello, en compañía de quienes nos son armónicos."60 Aconsejará a no pensar jamás en el vacío. ${ }^{61}$ Nos alecciona en el campo de la filosofía y de la literatura. Es un consejero inapreciable, un explorador de la verdad y de la belleza que nos da preciosos informes sobre lo que ha descubierto en sus incursiones. $\mathrm{E}$ iremos ${ }^{62}$ sobre lo inútil, de la rebusca de la originalidad;63 sobre la nada de la "gloriole"; 64 sobre la tolerancia que es la verdadera medida y así la honradez de la cultura; 65 sobre los críticos, que son "los blasés" del espíritu, ${ }^{66}$ sobre los libros de juventud, y los de experiencia. ${ }^{67}$ Indica los peligros de las obras que, por encantadoras que sean, no sirven de sostén interior. ${ }^{68}$

Decide: "Los útiles son nada, el talento es todo."69 Es saludable aún su manera de concebir la gloria,70 sabiendo que los inmortales se juntan al fin con los anónimos en el mismo olvido. ${ }^{71} \mathrm{Ah}$, cuánta sabiduría, cuánta cordura en sentencias cristalinas, o aceradas, o con el aspecto algunas, de una hoja de rosa. Nos ${ }^{72}$ es un preceptivo que engarza los mejores preceptos en su prosa de maestro; al par que pocos giias había que

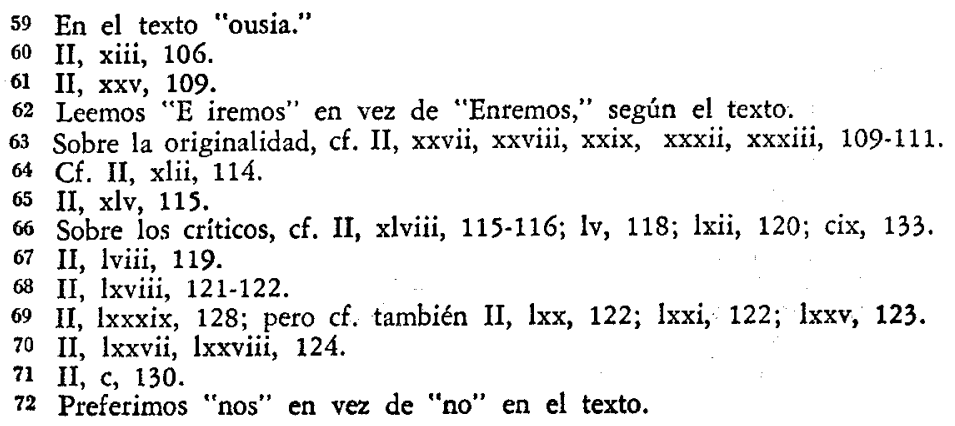


conduzcan mejor a la entrada de la selva de los genios, y del vergel, de los talentos. Os concentra a Dante ${ }^{73}$ o a Goethe. ${ }^{74} \mathrm{Y}$ al darnos el orgullo de la íntima conciencia, nos evita la inútil vanidad.

Ese grande patriota preconiza el alejamiento, ${ }^{75}$ en vez de la pasión, para sentir mejor el patriotismo. Previene contra el preciso bautismo del odio, en política. ${ }^{76}$ De cuando en cuando, entre apotegma y apotegma, el artista se despierta, $y$, pensariase que por vía de reposo, apunta un lindo paisaje, una visión en que le llama la naturaleza. ${ }^{77} \mathrm{Y}$ después vuelve a acuñar su áurea medalla, tras profundizar o ascender, y dice cosas como esta: "El más bello papel en la historia: Simón de Cirene."78 O esta: "QQué haría el águila si tuviese la cola del pavo real?"79 Pocos han entrado como él en el corazón de los poetas; pocos han ahondado más en el destino de los hombres. Y su optimismo se florecía de esperanza cuando se refería a nuestra raza, a los pueblos herederos de la civilización latina, cuya decadencia, proclamada por la desilusión o la prisa de algunos, parecíale un tiempo de espera, tras el cual había de venir la nueva ola de vigor conductor y creador. Varón sapiente, que estudió y vivió en su propio centro la activa civilización anglosajona, sabía que "los anglosajones están bien lejos de poder bastar solos al genio humano, y se engañarían si creyesen que ellos reflejan hoy los rayos más vivos." 80 Por otra parte, los americanos del Norte supieron apreciar el personaje diserto, prudente, lleno de luces, que supo representar entre ellos el prestigio de una nación junto con la tradición de una raza.

$Y$, antes de concluir, he de recordar cuán útil, cuán provechosa fue, no sólo para su país, sino para la personalidad moral de todas las repúblicas de nuestro continente, la presencia de aquel ciudadano insigne en su alto puesto, en la capital de los Estados Unidos.

El se atrevió a profetizar el fin de la guerra por el poder de las invenciones de la ciencia. ${ }^{81}$ Era un pacificador $y$ un animador. $Y$ su potente

73 Sobre Dante: II, clxxxvii, 157.

74 Sobre Goethe: II, lxxxvi, lxxxvii, 126-127.

75 III, i, 173.

76 III, $\mathrm{xxxi}, 182$.

77 III, xliii, 185-186, "Souvenir de Petrópolis"; xlvii, 187-189, "Souvenir du cimetière de Petrópolis."

78 III, Ixxxv, 201. Cf. San Mateo, xxvii. 32: "Y saliendo, hallaron a un Cireneo, que se llamaba Simón: a éste cargaron para que llevase su cruz." También San Marcos, xv. 21 y San Lucas, xxiii. 26.

79 III, cxliii, 222.

80 III, clxxiii, 236.

81 III, ccxix, 255. 
energía estaba realzada de suavidad. Oíd sus palabras: "La más bella de las profecías divinas: 'Bienaventurados los mansos porque ellos poseerán la tierra' ${ }^{82}$ Los cínicos no verán en ello más que una paradoja, $y$, sin embargo, si hay un hecho incontestable, de cada día, es que la dulzura obra por todas partes mucho más que la violencia, y que ella es la mayor fuerza en acción en el mundo." ${ }^{3}$

El ilustre Nabuco era-todos los que se le hayan acercado han podido comprobarlo-con lo imponente de su figura, con la autoridad de su discurso, con la imposición de sus gestos de hombre hecho para el mando y su hermosa cabeza ducal-era, digo, un ser de suavidad y de bondad, un intelectual sensitivo, que tendió de acuerdo con su principio, a llevar su pensamiento a la altura y a mantener su corazón en la tierra.

Yo le veo aún, en el cinematógrafo de mi memoria, más animado y más vivaz a medida que avanzábamos sobre el Atlántico, hacia las costas del Brasil. Y luego, cuando el entusiasmo de los hijos de Pernambuco se manifestó por él, en "tenders" floridos de banderas, sonoras de músicas, y llenos de gentes clamorosas y vibrantes, y pisó de nuevo su tierra original, ${ }^{84}$ en donde su juventud comprendiera la poesía patriarcal del antiguo "engenho," que más tarde le hiciera sentir lo que el paladín del abolicionismo llamara la nostalgia de la esclavitud. ${ }^{85} \mathrm{Y}$ después, a la llegada a Río de Janeiro, satisfecho del asombro encantado con que todos contemplábamos el panorama como a la entrada de un reino mágico, $y$, entre himnos y salutaciones, presentando a los estudiantes, a un diplomático cubano, que para él representaba allí el amor a la libertad, y a un modesto poeta, ${ }^{86}$ que encarnaba también alli, para él, el amor a la Belleza. Y desde entonces, desde esas escenas que evoco ante vosotros con una especie de emoción cariñosa, quedó para mí entre las figuras de mi culto tnental y cordial, la de aquél cuya grande alma me subyugó más

82 San Mateo, v. 5 (rev. de Cipriano de Valera): "Bienaventurados los mansos: porque ellos recibirán la tierra por heredad." Darío traduce la versión francesa de Nabuco.

83 III, ccxxvii, 260.

84 Véase Carolina Nabuco, Joaquim Nabuco, págs. 420-421, para algunos detalles más acerca de las escalas que hizo el vapor en el nordeste brasileño.

85 Darío recuerda la frase "la nostalgie de l'esclavage" que se halla en el "souvenir" "Massangana" (nombre del antiguo ingenio de los padrinos de Joaquim Nabuco), publicado en Pensées détachées, pág. 268.

86 Darío refiere algunos detalles de su llegada a Río de Janeiro en compañía de Nabuco en un artículo sobre Graça Aranha, en Obras completas, II, 967. 
tarde en sus obras, el ahijado de doña Anna Rosa Falcão de Carvalho, ${ }^{87}$ el libertador, el hombre ilustre que quiso el engrandecimiento de nuestro continente, $y$, en especial para su patria, riqueza, libertad, orden y progreso. 88

RUBÉN DARío

87 La madrina, casi madre, de Nabuco, figura prominentemente en el ensayo "Massangana." Cf. la nota 85.

88 En el texto "ordem e progresso," el lema nacional del Brasil; aparece no sabemos si por cortesía de Dario o por intervención del tipógrafo. 